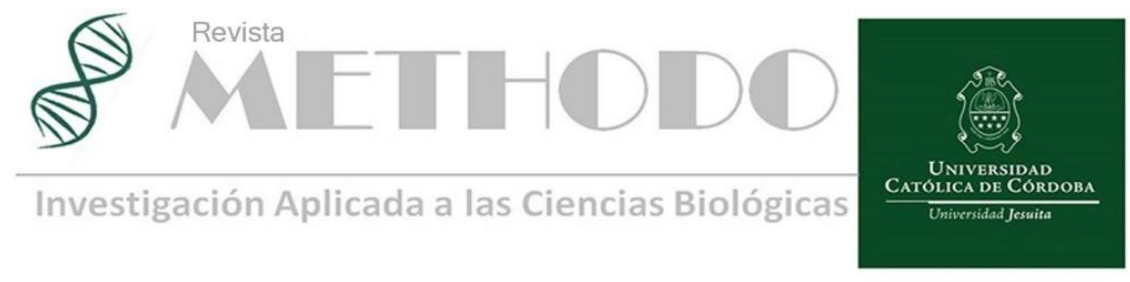

SEMBLANZA Rev. Methodo 2020;5(4):169-170

https://doi.org/10.22529/me.2020.5(4)09

Recibido. 21 Sep. 2020 | Publicado 05 Oct. 2020

\title{
Prof. Dr. Raúl Armando (1948 - 2002)
}

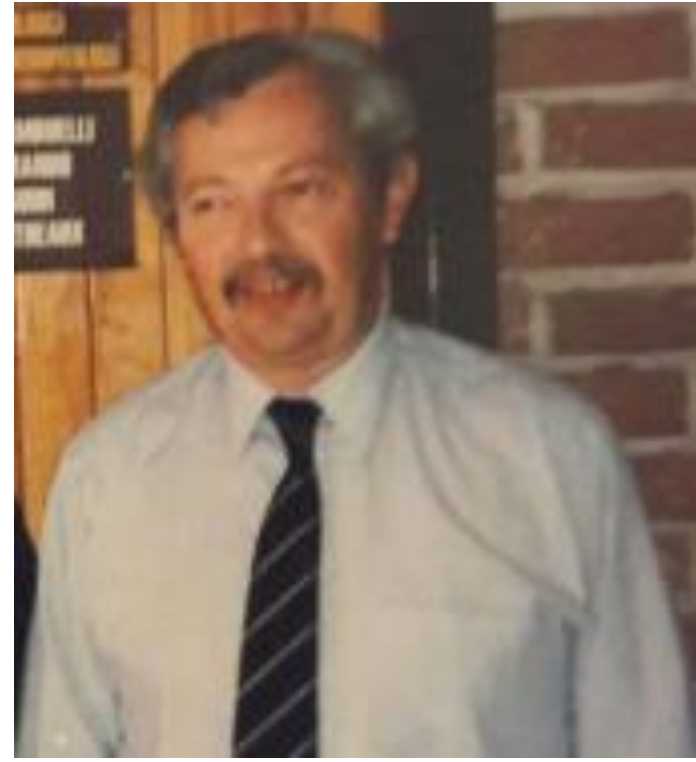

Figura 1. Prof. Dr. Raúl Armando

\section{Homenaje al Profesor Dr. Raúl Armando.}

El Prof. Dr. Raúl Armando nació el 22 de octubre de 1948 en Suardi, un pequeño pueblo en la provincia de Santa Fe, en límite estrecho con Córdoba. Tempranamente huérfano de madre, junto a Jorge su hermano mellizo fueron alumnos y pupilos en el Colegio de la Inmaculada de Santa Fe donde comienza su vínculo, siempre presente durante toda su vida, con los sacerdotes jesuitas, varios de ellos destinados a Córdoba para trabajar en la Obra de nuestra Universidad y Clínica.

Como muchos, desde allí vino a estudiar a nuestra Facultad de Medicina de donde egresa en el año 1971, quedando como docente en las Cátedras de Histología, Anatomía Patológica y Fisiopatología, además en la Clínica Universitaria Reina Fabiola trabajo como médico de guardia y simultáneamente junto al Dr. Rubén Sambuelli en el laboratorio de Patología, con quien compartió la docencia en grado y posgrado. Luego nos sumaríamos quienes fuimos sus primeros residentes y posteriormente sus compañeros de trabajo, el Dr. Andrés Guidi y quién escribe. Con el tiempo varios más serían formados por este equipo.

Entre los años 1985 y 1991 se desempeñó como Secretario Técnico de nuestra Facultad, acompañando al por entonces Decano Dr. José María Foscarini. Previo y posterior a este cargo durante varios años integra el Consejo de Profesores. En ambas situaciones lideró o acompañó numerosos proyectos.

Como patólogo formó parte de un equipo de gran influencia en el medio y por ello recibió casos de varias instituciones de salud de la ciudad de Córdoba, del interior y de provincias vecinas; siendo además consultado por numerosos especialistas en formación y ya formados. También se desempeñó en la salud pública durante casi 30 años como patólogo en el Servicio del Hospital Rawson.

El 2 de noviembre de 1999 fiel a su perfil de líder y gestor funda y es elegido como primer presidente de la Asociación de Patólogos de la Provincia de Córdoba, entidad gremial mediante la cual logra unir a colegas que por entonces estaban

Revista Methodo: Investigación Aplicada a las Ciencias Biológicas. Universidad Católica de Córdoba. Jacinto Ríos 571 Bo Gral. Paz. X5004FXS. Córdoba. Argentina. Tel.: (54) 351 4517299 / Correo: methodo@ucc.edu.ar / Web: methodo.ucc.edu.ar | SEMBLANZA Rev. Methodo 2020;5(4):169-170. 
marcadamente distanciados y posiciono a la especialidad en un lugar de reconocimiento en el medio y al servicio de todos. Años después la por entonces Presidente Dra. Alicia Henín, en un discurso frente a la audiencia de la ya consolidada Asociación escribiría:

"El promotor más importante que tuvo la Asociación fue el Dr. Raúl Armando, quien falleciera a muy temprana edad. Su perseverancia en tratar de unir a todos los especialistas y en reclamar acciones urgentes desde la Sociedad Argentina de Patología para crear una Federación Nacional son reconocidas por todos...".

Como docente se desempeña en el grado como Profesor Adjunto de las asignaturas de Histología, Anatomía Patológica y desde 1993 como Profesor Titular de Histología 1. Del mismo modo, en el posgrado es nombrado Profesor de asignaturas afines a la especialidad, la cuál es una de las tres primeras residencias y posteriormente carrera de nuestra institución.

El 10 de diciembre de 2002 fallece a los 54 años en forma repentina e inesperada. En ese momento se desempeñaba como Director General de la Clínica y a partir de marzo del año siguiente tomaría además el cargo de Decano de la Facultad, una vez más con el firme propósito de lograr un trabajo en común en pos del crecimiento y desarrollo de ambas estructuras.

Pienso que un gran profesor es aquel que conoce y domina su ciencia y llega efectivamente a transmitir sus conocimientos a sus alumnos. Un Maestro es un gran profesor que se compromete, involucra y disfruta con el crecimiento y desarrollo de sus discípulos, dando oportunidades en libertad. El Maestro ama y respeta su institución como a un hogar; a sus colegas como a una familia; y a sus discípulos como a sus hijos. Sin lugar a dudas Raúl Armando fue para los que estuvimos a su lado un Maestro. Vaya aquí un pequeño homenaje a su memoria y para la que fuera su compañera de toda la vida, su esposa María de los Ángeles Bajo (Nenu), su hija Laura y su hijo Lucas, nuestro actual compañero y amigo.

\section{Prof. Dr. Ricardo Theaux.}

(Director General de la Clínica Universitaria Reina Fabiola. Universidad Católica de Córdoba. Facultad de Ciencias de la Salud. Cátedras de Histología y Anatomía Patológica.)

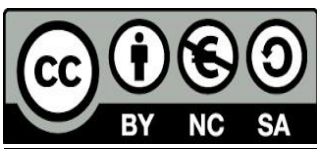

